\title{
Utilization of HIV and Sexually Transmitted Infections Prevention Services, and Associated Factors among the Long-Distance Truck Drivers along the Northern Corridor Highway, Kenya
}

\author{
Cyrus Mutie ${ }^{1 *}$, Salome Kairu-Wanyoike², Susan Mambo1, Reagan Ngoge ${ }^{1}$, John Gachohi1,3 \\ ${ }^{1}$ School of Public Health, Jomo Kenyatta University of Agriculture and Technology, Nairobi, Kenya \\ ${ }^{2}$ Meat Training Institute, Ministry of Agriculture, Livestock, Fisheries and Cooperatives, Nairobi, Kenya \\ ${ }^{3}$ Washington State University-Global Health Program, Nairobi, Kenya \\ Email: *paulmutiecyrus@gmail.com
}

How to cite this paper: Mutie, C., Kairu-Wanyoike, S., Mambo, S., Ngoge, R. and Gachohi, J. (2021) Utilization of HIV and Sexually Transmitted Infections Prevention Services, and Associated Factors among the Long-Distance Truck Drivers along the Northern Corridor Highway, Kenya. Advances in Sexual Medicine, 11, 39-58. https://doi.org/10.4236/asm.2021.113003

Received: April 22, 2021

Accepted: June 1, 2021

Published: June 4, 2021

Copyright $\odot 2021$ by author(s) and Scientific Research Publishing Inc. This work is licensed under the Creative Commons Attribution International License (CC BY 4.0).

http://creativecommons.org/licenses/by/4.0/ (c) (i) Open Access

\begin{abstract}
Background: Often, long-distance truck drivers' (LDTDs') work predisposes them to sexually transmitted infections (STIs) whose outcomes are influenced by access and behavior of seeking sexual health care. Methodology: In this study, we assessed the utilization of HIV/STI preventive services and associated factors among 296 LDTDs operating along the northern corridor highway using an interviewer-administered questionnaire for data collection at Mlolongo stopover in Machakos, Kenya. Responses for the investigated variables, including condom use, history of HIV testing, frequency of HIV testing, antiretroviral therapy (ART) use and follow-up for the HIV positive and STI treatment, were assigned a score of either 1 or 0 depending on the question's dimension. Following summing up for each participant, we computed a weighted score ranging between 0 and 1 by dividing the summed responses by the number of eligible variables. We arbitrarily multiplied these scores by 8 to generate endpoint scores ranging from one to eight for each participant to help create a dichotomized outcome variable for utilization levels: limited utilization (1 to 4 ) and good utilization (5 to 8). Association between certain independent variables and the outcome variable (level of utilization of H.I.V./STIs preventive services) was analyzed using binomial logistic regression analysis in R statistical software. Results: The mean age of the LDTDs was 38.4 years, ranging from $24-57$ years. The majority $(n=287,97 \%)$ of the LDTDs had been tested on HIV at least once since the beginning of their career. Only $4.9 \%$ of the LDTDs had been tested on HIV within the previous three months. Of the 175 LDTDs who reported a history of STI, most $(\mathrm{n}=$ $173,98.9 \%$ ) of them had sought treatment. Condom use rates were higher
\end{abstract}


(97.1\%) among the LDTDs who had sexual interactions with casual sexual partners compared to $47.2 \%$ among regular sexual partners. Analyses classed most of the respondents $(n=231,78.0 \%)$ as having good utilization, while the rest $(22 \%)$ had limited utilization. History of STI was independently associated with utilizing HIV/STI preventive services (OR 8.4; 95\% CI; 4.5, 16.7; P < 0.001). Conclusion: Although most of the LDTDs were classed to have good utilization of HIV/STI preventive services, the uptake of subsequent HIV testing services among them was low at only $4.9 \%$. The association of STI history with utilization levels that we determined supports policies of integrating HIV and STI services in the delivery of sexual healthcare provision among LDTDs.

\section{Keywords}

Utilization, Factors, Sexually Transmitted Infections, HIV/STI Services, Long-Distance Truck Drivers, Northern Corridor Highway, Kenya

\section{Introduction}

Long-distance truck drivers (LDTDs) are central to the challenges faced in the fight against HIV and sexually transmitted infections (HIV/STIs) in large part due to escalated risk of new infections arising from the nature of their career [1] [2]. Moreover, the risk of HIV and STI infection outcomes among the LDTDs is partly attributable to sub-optimal access and underutilization of HIV/STI preventive services [3]. These two factors (heightened risk and underutilization of HIV/STI preventive services) have placed the LDTDs among at-risk populations that need targeted interventions for effective control of HIV [1].

Evidence that LDTDs do not adequately utilize the HIV/STI preventive services, especially when on transit is available. For instance, in Mozambique, Botao et al. [4] reported that only $65.8 \%$ of the LDTDs had been tested on HIV. Likewise, in Togo, Yaya et al. [5] described $47.4 \%$ of LDTDs that had accessed HIV testing previously. In Nigeria, Atilola et al. [6] identified low utilization levels (36.4\%) of HIV testing among the LDTDs. A study in South Africa reported a low uptake of STI treatment services among LDTDs who frequented wellness clinics [3]. In Kenya, a study reported a paltry $1.3 \%$ of LDTDs taking self-driven HIV testing [7].

Key challenges continue to negatively shape the utilization of HIV/STI preventive services among LDTDs. Lack of adequate health facilities and services specifically tailored for the LDTDs has impaired their smooth access to STI treatment in Pakistan [8]. In a study conducted in Mozambique, 75\% of the LDTDs interviewed had not received free condoms, lubricants, and HIV/STI preventive information in the previous 12 months [4]. In New Mexico, study respondents disclosed that lack of health insurance cover, mistrust, lack of confidentiality from health care providers, and inability to keep hospital appointment dates hindered them from meeting their health care needs [9]. In Zambia, 
tight work schedules, with very little time to rest among LDTDs posed difficulties in utilizing HIV/STI preventive services [10]. Recently, delays due to COVID-19 clearance requirements among LDTDs could have adversely affected their uptake of key public health services [11].

The low utilization of HIV/STIs preventive services among the LDTDs has been linked to a high HIV prevalence among them. To illustrate this, a study done at Kwa-Zulu Natal in South Africa along the North-South Corridor highway revealed an HIV prevalence of 56\% among the LDTDs [12]. In Uganda, the LDTDs had an HIV prevalence ranging between 25\% to $32 \%$ [13]. A similar population had an HIV prevalence of $17.8 \%$ in Kenya [14].

While the existing literature shows limited utilization of HIV/STI preventive services among the LDTDs, opportunities exist to optimize the uptake. In Tanzania, a dated study explained that peer interventions among the LDTDs could improve the utilization of condom use by $50 \%-74 \%$ [15]. Literature shows that offering oral HIV testing among the LDTDs in Kenya at the wellness centers along the highway improved HIV testing uptake [16]. Information on the availability of HIV testing via mobile phone text has also been shown to increase the uptake of these services among LDTDs in Kenya [7].

Nevertheless, data on the uptake of HIV/STI preventive services among the LDTDs in Kenya is scanty. This study, therefore, sought to assess the levels of utilization of HIV/STI preventive services and associated factors among the LDTDs who operate along the northern corridor highway in Kenya. This study could aid the policymakers involved in HIV programming in improving the current policies in the fight against HIV and other STIs among the LDTDs.

\section{Methodology}

\subsection{Research Design}

We conducted a cross-sectional study among LDTDs who made a stop at a wayside weighbridge in Mlolongo town in Machakos, Kenya, between July and August 2020. Besides taking the weight of the trucks, the town is a key destination for commercial sex work and offering restful accommodation services [17]. Therefore, this was a suitable site for our study, given that almost all LDTDs have to make a stopover there. The sample size of the study participants, calculated using formal sample size calculation procedures, was 296. We applied a systematic sampling technique using a daily sampling size of 21 and a sampling interval of 20 to sample the LDTDs.

\subsection{Data Collection Instruments}

We implemented an interviewer-administered questionnaire as a tool for data collection. The study adopted this tool from a World Health Organisation (WHO) generic tool designated for conducting HIV and STIs research [18]. We also consulted the guidelines in previous studies in questionnaire development [19] [20]. 


\subsection{Pre-Testing of Data Collection Instruments}

The study commenced with a pre-testing of data collection tools at the neighboring Makutano town in Machakos County. The town is used as a stopover for rest and commercial sex but on a significantly lower scale relative to our study site along the Northern Corridor highway. In this exercise, we recruited 30 participants considering the sample size recommended for a study to achieve a power of $80 \%$ [21].

\subsection{Data Collection}

The LDTDs were initially approached at a wayside parking towards the exit of the weighbridge for a detailed introduction of the study. Those who expressed willingness to participate in the study were further taken through an informed consent, which they formally signed before the onset of the interview. Given the sensitive nature of some of the questions in our questionnaire, most of the LDTDs understandably requested to be interviewed inside the truck driver's cabin, safeguarding privacy during the interview process. Data on the history and trends of the utilization of HIV/STI preventive services among the LDTDs were collected.

\subsection{Data Management and Analysis}

A database was designed in MS Excel ${ }^{\circledR}$, and data from the questionnaires were entered, followed by data cleaning and exportation to the R statistical software [22] for analysis. Descriptive statistics were generated regarding the socio-demographic and socio-economic characteristics, history of HIV and STIs, and levels of utilization of HIV/STI preventive services. A composite outcome variable on utilization of HIV/STIs preventive services was derived from; condom use, history of HIV testing, frequency of HIV testing, antiretroviral therapy (ART) use, and follow-up for the HIV positive and STI treatment. On their own, the individual variables could not give a conclusive level of the utilization of HIV/STI preventive services among the LDTDs, hence the need for the composite variable [23]. The selection of the original variables used to create the composite variable was based on the relevance of the variable in the utilization of HIV/STI preventive services as guided in previous research [23].

Responses from the investigated variables, including condom use, history of HIV testing, frequency of HIV testing, ART use, and follow-up for the HIV positive and STI treatment, were assigned a score of either 1 or 0 depending on the question's dimension. Following summing up for each participant, we computed a weighted score ranging between 0 and 1 by dividing the summed responses by the number of eligible variables. We arbitrarily multiplied these scores by 8 to generate endpoint scores ranging from one to eight for each participant to help create a dichotomized outcome variable for utilization levels: limited utilization (1 to 4 ) and good utilization (5 to 8 ). The numerator (total scores of all eligible responses) was derived as follows; Condom use $(1,0)+$ His- 
tory of HIV testing $(1,0)+$ Frequency of HIV testing Within the last three months $(1,0)$ or Within 3-6 months ago $(0.5)$ or Tested in more than six months ago + ART use $(1)+$ STI treatment $(1,0)$. The denominator was the number of eligible questions. The weighted mean was then multiplied by a constant (8) to place the scores in the range of between one and eight, as shown in the equation:

$$
\text { Composite score }=\frac{\text { Total scores of all eligible responses }}{\text { Number of eligible questions }} \times 8
$$

Association between the independent variables and the outcome variable (level of utilization of HIV/STIs preventive services) was determined using binomial logistic regression analysis in $\mathrm{R}$ statistical software [22].

\subsection{Ethical Considerations}

Informed consent was sought from each LDTD before commencing the interview exercise. The anonymity of all LDTDs was observed throughout the data collection exercise to ensure confidentiality. The data enumerators were sworn to a confidentiality form before starting the data collection exercise to ensure the privacy of the study participants. Questionnaires were stored in a locked cabinet, while data was stored in coded form and secured with passwords for confidentiality. The ethical review committee of the University of Eastern Africa Baraton (UEAB/REC/10/02/2020) approved this study. Data collection was authorized by the board of postgraduate studies, Jomo Kenyatta University of Agriculture and Technology, Kenya (JKU/2/11/HSH/314-1277/2018). Additionally, the National Commission for Science, Technology, and Innovation, Kenya, issued a license and permit to conduct this study (NACOSTI/P/20/4107).

\section{Results}

\subsection{Socio-Demographic and Socio-Economic Characteristics of the Study Participants}

Table 1 shows the socio-demographic and socio-economic characteristics of 296 LDTDs involved in this study. The mean age of the LDTDs was 38.4 years, ranging from 24 to 57 years. The majority of the LDTDs were aged between 35 and 44, whereas the minority were aged between 55 - 66 years. The majority of the LDTDs (65.9\%) had attained secondary school education, while only $2 \%$ had attained a college education. Most (80.4\%) of the LDTDs reported that they were married, while in terms of religion, most of them (78.0\%) were Christians. Approximately half (49.3\%) of the LDTDs had work experience of above ten years, with $96.3 \%$ of them earning below 500 US dollars in a month (Table 1 ).

\subsection{Uptake of the HIV Prevention Services among the Long-Distance Truck Drivers}

\subsubsection{HIV Testing Trends among the Long-Distance Truck Drivers}

The majority ( $n=287,97 \%$ ) of the LDTDs who were interviewed reported having been tested for HIV at some point since the start of their career. At the time 
of conducting this study, only $4.9 \%$ of the LDTDs had been tested on HIV in the previous three months. Out of the 287 LDTDs reporting HIV testing, only 4.5\% had utilized both finger prick and oral HIV testing. The majority of the LDTDs (97.9\%) reported a negative HIV outcome from their last HIV test (Table 2).

Table 1. Socio-demographic and socio-economic characteristics of the LDTDs.

\begin{tabular}{|c|c|c|}
\hline Variable & Frequency (n) & Percentage (\%) \\
\hline \multicolumn{3}{|l|}{ Age } \\
\hline $18-24$ & 3 & 1.0 \\
\hline $25-34$ & 98 & 33.1 \\
\hline $35-44$ & 126 & 42.6 \\
\hline $45-54$ & 65 & 22.0 \\
\hline $55-64$ & 4 & 1.4 \\
\hline \multicolumn{3}{|l|}{ Citizenship } \\
\hline Kenya & 233 & 78.7 \\
\hline Uganda & 36 & 12.2 \\
\hline Tanzania & 13 & 4.4 \\
\hline Rwanda & 8 & 2.7 \\
\hline South Sudan & 6 & 2.0 \\
\hline \multicolumn{3}{|l|}{ Education } \\
\hline Primary & 72 & 24.3 \\
\hline Secondary & 195 & 65.9 \\
\hline Vocational & 23 & 7.8 \\
\hline College & 6 & 2.0 \\
\hline \multicolumn{3}{|l|}{ Marital Status } \\
\hline Single & 31 & 10.5 \\
\hline Married & 238 & 80.4 \\
\hline Divorced & 4 & 1.4 \\
\hline Cohabiting & 23 & 7.8 \\
\hline \multicolumn{3}{|l|}{ Religion } \\
\hline Christian & 231 & 78.0 \\
\hline Muslim & 65 & 22.0 \\
\hline \multicolumn{3}{|c|}{ Years working as a truck driver } \\
\hline Less than one year & 5 & 1.7 \\
\hline One to three years & 45 & 15.2 \\
\hline Four to five years & 34 & 11.5 \\
\hline Six to ten years & 66 & 22.3 \\
\hline Above ten years & 146 & 49.3 \\
\hline
\end{tabular}




\section{Continued}

\begin{tabular}{ccc}
\hline Weeks away on a transit journey & & \\
\hline Less than seven days & 116 & 39.2 \\
One week & 91 & 30.7 \\
Two weeks & 83 & 28.0 \\
Three weeks & 6 & 2.0 \\
\hline Income level & & \\
\hline$<500$ USDs (<50,000 K.Shs) & 285 & 96.3 \\
$\geq 500$ USDs ( $\geq 50,000$ K.Shs $)$ & 11 & 3.7 \\
\hline
\end{tabular}

Table 2. HIV testing characteristics among LDTDs along the Northern Corridor highway, Kenya, 2020.

\begin{tabular}{|c|c|c|}
\hline Variable & Frequency (n) & Percentage (\%) \\
\hline History of HIV testing & $\mathrm{n}=296$ & \\
\hline Yes & 287 & 97 \\
\hline No & 9 & 3 \\
\hline Duration after last HIV test & $\mathrm{n}=287$ & \\
\hline Three months ago & 14 & 4.9 \\
\hline Four to Six months ago & 100 & 34.8 \\
\hline Above Six months ago & 173 & 60.3 \\
\hline Type of HIV test & $\mathrm{n}=287$ & \\
\hline Finger Prick & 274 & 95.5 \\
\hline Finger prick and Oral & 13 & 4.5 \\
\hline HIV test outcome & $\mathrm{n}=287$ & \\
\hline Negative & 281 & 97.9 \\
\hline Positive & 6 & 2.1 \\
\hline Challenges faced in HIV testing & $\mathrm{n}=287$ & \\
\hline Lack of necessary equipment & 10 & 3.5 \\
\hline Healthcare providers' negative attitude & 20 & 7 \\
\hline Self-stigma & 32 & 11.1 \\
\hline Delays while on transit & 130 & 45.3 \\
\hline No challenges faced & 95 & 33.1 \\
\hline Health facilities from which HIV testing was accessed & $\mathrm{n}=287$ & \\
\hline NGO based health facility & 154 & 53.7 \\
\hline Public health facility & 87 & 30.3 \\
\hline Private health facility & 46 & 16 \\
\hline
\end{tabular}

\subsubsection{Challenges Faced in Access to HIV Testing Services}

Of the 287 LDTDs who reported HIV testing before, $45.3 \%$ of them reported time delays as their main challenge in accessing HIV testing services. In contrast, the minority (7\%) cited negative attitudes from health care providers (Table 2).

\subsubsection{Antiretroviral Therapy Uptake and Follow up on Care}

All the six LDTDs who tested HIV positive before, had been started on antire- 
troviral therapy (ART) therapy and already on follow-up and care in different health facilities. When asked about the challenges they faced while accessing their ART therapy, three participants reported no challenges at all, two reported having missed one of their scheduled follow-up and ART refill appointments due to delays at the international border points. One LDTD reported having missed one of his follow-up and ART refill appointments at some point when he tested positive for COVID-19 and was isolated for 21 days.

\subsection{History of Sexually Transmitted Infections and Treatment among the Long-Distance Truck Drivers}

A majority (59.1\%) of the LDTDs disclosed infections with an STI since their career onset. Of those who reported having ever contracted an STI, majority (98.9\%) sought treatment while the rest did not. Of those who reported that they had sought treatment, $96.0 \%$ reported doing so within seven days. Approximately half (48.6\%) of the LDTDs sought STI treatment from non-governmental health-based facilities. About a third of the LDTDs had never faced challenges while accessing STI treatment services (Table 3).

Table 3. STI infections and treatment among LDTDs along the Northern Corridor highway, Kenya, 2020.

\begin{tabular}{|c|c|c|}
\hline Variable & Frequency (n) & Percentage (\%) \\
\hline History of STI infection & $\mathrm{n}=296$ & \\
\hline Yes & 175 & 59.1 \\
\hline No & 121 & 40.9 \\
\hline Sought for STI treatment & $\mathrm{n}=175$ & \\
\hline Yes & 173 & 98.9 \\
\hline No & 2 & 1.1 \\
\hline Sought for STI treatment after how long & $\mathrm{n}=173$ & \\
\hline Within 7 days & 166 & 96.0 \\
\hline After a period exceeding 7 days & 7 & 4 \\
\hline $\begin{array}{l}\text { Health facilities from which } \\
\text { STI treatment was sought from }\end{array}$ & $\mathrm{n}=173$ & \\
\hline Non-governmental based health facility & 84 & 48.6 \\
\hline Public health facility & 77 & 44.5 \\
\hline Private health facility & 12 & 6.9 \\
\hline Challenges in access to STI treatment services & $\mathrm{n}=173$ & \\
\hline Lack of access to drugs & 6 & 3.5 \\
\hline Lack of health insurance cover & 7 & 4 \\
\hline Health care providers' negative attitude & 21 & 12.1 \\
\hline Self-stigma & 36 & 20.8 \\
\hline Delays while on transit & 48 & 27.7 \\
\hline No challenges faced at all & 55 & 31.8 \\
\hline
\end{tabular}




\subsection{Condom Use among the Long-Distance Truck Drivers}

Of the 141 Long-distance truck drivers who reported sexual interactions, 84.4\% of them had used condoms. Slightly below half (47.2\%) of the 36 LDTDs who had sexual interaction with regular partners used condoms while the rest (53.8\%) did not. The LDTDs who had sexual interactions with casual sex partners had the highest rates of condom use, with $97.1 \%$ of them reporting condom use. A majority (81.8\%) of the LDTDs reporting no condom use claimed to have not perceived any risk of STI infection during their sexual interactions.

Approximately $42.2 \%$ of the LDTDs accessed condoms from bars or other entertainment joints while on transit. The majority of the LDTDs $(72.6 \%)$ had never lacked condoms in a time of need, while the rest reported that at some point, they had lacked condoms when they needed them. Most LDTDs (69.3\%) had never experienced challenges while accessing condoms (Table 4).

Table 4. Condom use among LDTDs along the Northern Corridor highway, Kenya, 2020.

\begin{tabular}{|c|c|c|}
\hline Variable & Frequency (n) & Percentage (\%) \\
\hline Condom use among truck drivers & $\mathrm{n}=141$ & \\
\hline Yes & 119 & 84.4 \\
\hline No & 22 & 15.6 \\
\hline Condom use among LDTDs who had sexual interaction with regular partners & $\mathrm{n}=36$ & \\
\hline Yes & 17 & 47.2 \\
\hline No & 19 & 52.8 \\
\hline Condom use among LDTDs who had sexual interaction with casual partners & $\mathrm{n}=105$ & \\
\hline Yes & 102 & 97.1 \\
\hline No & 3 & 2.9 \\
\hline No perceived risk of infection & 18 & 81.8 \\
\hline Need to have maximized pleasure from unprotected sexual intercourse & 4 & 22.2 \\
\hline Source of condoms & $\mathrm{n}=296$ & \\
\hline From bars or other entertainment joints & 125 & 42.2 \\
\hline Never in need of them at all & 27 & 9.1 \\
\hline Purchase from a privately owned facility (pharmacies or chemists) & 29 & 9.8 \\
\hline Public health facility & 62 & 21.0 \\
\hline Non-governmental health facility & 53 & 17.9 \\
\hline Ever lacked condoms in a time of need & $\mathrm{n}=296$ & \\
\hline No & 215 & 72.6 \\
\hline Challenges while accessing condoms & $\mathrm{n}=296$ & \\
\hline Unavailability or stockouts from bars or other entertainment joints & 73 & 24.7 \\
\hline No challenges encountered at all & 205 & 69.3 \\
\hline Unavailability from the public health facility & 12 & 4.1 \\
\hline Unable to afford them from (pharmacies or chemists) & 6 & 2.0 \\
\hline
\end{tabular}




\subsection{Utilization Levels of HIV/STIs Preventive Services}

From the composite variable we generated, most of LDTDs (78.0\%) were classed to have good utilization of HIV/STIs preventive services (5 - 8), while the rest (22\%) had limited utilization (1 - 4).

\subsection{Factors Associated with the Utilization of HIV/STIs Preventive Services}

A univariable analysis using the binomial logistic regression was performed to determine the factors associated with the utilization of HIV/STIs preventive services among the LDTDs. We used the odds ratio to estimate the strength of association between the independent and dependent variables. The level of significance was set at $\mathrm{p}<0.05$. Only the variables with $\mathrm{p}<0.1$ at univariable binomial logistic regression level entered the multivariable binomial logistic regression level of analyses. The association between the utilization of HIV/STI preventive services with the History of STIs and with stigma was statistically significant at univariable analyses (Table 5).

A multivariable binomial logistic regression was performed to control for confounding in significant factors identified at the univariate step. Only the history of STIs among the LDTDs was independently associated with the utilization of HIV/STIs preventive services among LDTDs involved in the study (OR 8.4; 95\% CI; 4.5, 16.7; P < 0.001). The LDTDs who reported a history of STIs were 8.4 times more likely to have utilized the HIV/STIs preventive services compared to those who did not have a history of an STI.

Table 5. Univariable binomial logistic regression model of factors associated with utilization of HIV prevention services among LDTDs, along the Northern Corridor highway, Kenya, 2020.

\begin{tabular}{|c|c|c|c|}
\hline Variable & OR & $95 \% \mathrm{CI}$ of OR & P-value \\
\hline Age & 1.02 & $0.98,1.05$ & 0.423 \\
\hline Citizenship & 1.25 & $0.64,2.61$ & 0.530 \\
\hline Marital status & 1.04 & $0.55,1.94$ & 0.908 \\
\hline Religion & 1.16 & $0.60,2.37$ & 0.666 \\
\hline Education & 1.33 & $0.81,2.17$ & 0.259 \\
\hline Duration working as LDTD & 1.15 & $0.80,1.65$ & 0.443 \\
\hline Monthly income & 0.74 & $0.21,3.46$ & 0.666 \\
\hline Time away on transit & 1.27 & $0.91,1.79$ & 0.172 \\
\hline History of STI & 8.38 & $4.46,16.65$ & $<0.001$ \\
\hline Health-care provider's attitude to LDTDs & 2.29 & $0.76,9.86$ & 0.19 \\
\hline Self-Stigma & 5.42 & $1.90,22.85$ & 0.006 \\
\hline Time delays on the highway & 1.06 & $0.61,1.86$ & 0.828 \\
\hline
\end{tabular}

Odds Ratio (OR), 95\% Confidence Intervals (95\% CI), P $<0.05$. 


\section{Discussion}

\subsection{Utilization of HIV/STI Preventive Services}

This study assessed the utilization levels of HIV/STI preventive services and associated factors among the LDTDs. Analyses classed most of the respondents (n $=231,78.0 \%)$ as having good utilization, while the rest (22\%) had limited utilization. An STI history was strongly associated $(\mathrm{OR}>8)$ with the utilization of HIV/STI preventive services.

The study findings reveal that despite the high number of LDTDs undergoing HIV testing (97\%), the uptake of the subsequent tests (as recommended after every three months) is still low (4.9\%). In such circumstances, the identification of new HIV cases among the LDTDs could be difficult. As a result, late HIV diagnosis misses the early initiation to antiretroviral therapy and continues to bridge the infection to other sexual partners. Nevertheless, there is an opportunity to improve the uptake of the subsequent HIV tests to meet the recommended frequency of 3 monthly testing for the most at-risk populations, including LDTDs. The $97 \%$ of LDTDs previously tested for HIV in this study are comparable to $91.8 \%$ reported in 2018 in Kenya, suggesting recent improvements in national HIV testing among the LDTDs [24]. Studies in Mozambique and Togo reported lower proportions (65.8\% and $47.7 \%$ respectively) of HIV testing among the LDTDs, perhaps a reflection of lesser national HIV testing [4] [5].

Of the LDTDs previously HIV tested, $95.5 \%$ had only received the provider-administered finger prick test. In contrast, only $4.5 \%$ of the LDTDs had ever utilized oral HIV tests. This outcome indicates that the oral HIV testing uptake is unacceptably low among the LDTDs, despite strong recommendations from UNAIDS [25]. Research shows that availing the oral HIV test kits to the LDTDs may improve their uptake on HIV testing [7]. Indeed, the reason for their recommendation is the non-invasive nature enabling ease of use without healthcare provider involvement [7]. Therefore, reasons as to the low (4.9\%) uptake of the oral HIV tests need to be investigated.

Slightly above half (59.1\%) of the LDTDs reported contracting an STI during their career, suggesting minimal condom use during their sexual interactions. However, it was notable that almost all (98.9\%) of the LDTDs who contracted the STIs sought treatment. Prompt STI treatment provides a strong prognosis of recovery and reduces chances of HIV transmission between sexual partners. Contrary to our findings, a previous study on the same population conducted a decade earlier found smaller proportions of $15 \%$ of LDTDs reporting an STI history, perhaps reflecting a change of practices with time [17].

Most of the LDTDs (78.0\%) reported good utilization of the HIV/STI preventive services (scores of $5-8$ ), while the rest (22\%) had limited utilization (scores of 1 - 4). The proportion of LDTDs (22\%) who had limited utilization highlights the need for enhanced interventions. These interventions need to be tailored to meet the unique healthcare needs of the LDTDs. Policy guidelines on HIV programming (HIV testing, care, and treatment) recommend integrating STI and 
HIV preventive services like; HIV testing and counselling and condom distribution to the vulnerable groups [26]. Integrating the STI and HIV preventive services has the advantage of improving the overall utilization of the HIV preventive services while being cost-effective [26]. The outcome in utilizing HIV/STI preventive services supports the guidelines for integrating HIV and STI services. Contrary to our findings on $78 \%$ of LDTDs reporting good utilization of HIV preventive services, a study in South Africa found that only $30 \%$ of the study participants had good utilization [3].

Of the LDTDs who reported sexual interactions with casual sexual partners, $97.1 \%$ of them used condoms. For the LDTDs who had sexual interactions with regular sexual partners, only $47.2 \%$ of them used condoms. From these findings, it is evident that the exposure risk to HIV and STIs is high among the LDTDs engaging regular sexual partners implying that intense HIV/STI control efforts need to include this segment, previously neglected relative to those engaging in casual sex. Consistent with our findings, previous studies in Nigeria, South Africa, and Mozambique have identified low rates of condom use in sexual interactions between LDTDs and regular sexual partners as opposed to higher rates among casual partners [1] [4] [27].

\subsection{Factors Associated with the Utilization of HIV/STI Preventive Services}

Only the history of STIs among the LDTDs was significantly and strongly associated with the utilization of HIV/STI preventive services $(\mathrm{OR}=8.4)$. These findings imply that the LDTDs who contracted STIs and sought treatment in various health facilities also benefited from other HIV/STI preventive services such as accessing condoms and HIV testing. The findings also suggest that the health care providers who attend the LDTDs should also create awareness of preventing future STIs. Recent guidelines recommend that patients who present with STIs obtain HIV testing to avoid missed opportunities for identifying new HIV cases [25] since STIs elevate the risk of HIV infection. The chances are that the LDTDs presenting with STI symptoms may also have been exposed to HIV attributable to similar transmission mode [26]. While these findings are consistent with those of other studies done in Zambia and Brazil reporting a significant association between STI and utilization of HIV/STI preventive services [28] [29], a study in the USA reported no significant association between the history of STIs and the uptake of HIV preventive services [30]. Our findings suggest that in enhancing the utilization of H.I.V./STIs preventive services, LDTDs should be encouraged to bring along their sexual partners for STI/HIV health care services whenever they have an STI. The ultimate goal would be to maximize the utilization of HIV/STI preventive services among the most at-risk populations and the general population, thus reducing new HIV and STI infections.

\subsection{Study Limitations}

Given the discomfort that may arise from questions touching on sexual interac- 
tions, responses given by the LDTDs were likely to have social-desirability bias, where respondents over-report the good behavior and under-report the bad behavior. To minimize the social-desirability bias, we ensured that confidentiality prevailed throughout the study while detailing the potential benefits of the study to the LDTDs health well-being during interviews.

\section{Conclusion}

Despite the $78 \%$ of good utilization of HIV/STI preventive services, uptake of the subsequent HIV testing among the LDTDs is still low at $4.9 \%$, calling for enhanced HIV testing among the LDTDs. The history of an STI among the LDTDs is a predictor of utilization of HIV/STI preventive services. Therefore, a recent history of an STI may open an opportunity for providing other HIV preventive services among the LDTDs like HIV testing and access to condoms.

\section{Acknowledgements}

We thank the Long-distance truck drivers operating along the Northern Corridor highway for their corporation during data collection, which made the study a success.

\section{Conflicts of Interest}

The authors declare no conflicts of interest regarding the publication of this paper.

\section{References}

[1] Makhakhe, N.F., Lane, T., McIntyre, J. and Struthers, H. (2017) Sexual Transactions between Long Distance Truck Drivers and Female Sex Workers in South Africa. Global Health Action, 10, Article ID: 1346164. https://doi.org/10.1080/16549716.2017.1346164

[2] Apostolopoulos, Y., Sönmez, S., Shattell, M.M. and Belzer, M. (2010) Worksite-Induced Morbidities among Truck Drivers in the United States. Journal of the American Association of Occupational Health Nurses, 58, 285-296. https://doi.org/10.1177\%2F216507991005800703

[3] Lalla-Edward, S.T., Ncube, S., Matthew, P., Hankins, C.A., Venter, W.F. and Gomez, G.B. (2017) Uptake of Health Services among Truck Drivers in South Africa: Analysis of Routine Data from Nine Roadside Wellness Centres. BMC Health Services Research, 17, Article No. 649. https://doi.org/10.1186/s12913-017-2595-3

[4] Botão, C., Horth, R.Z., Frank, H., Cummings, B., Inguane, C., Sathane, I., McFarland, W., Fisher Raymond, H. and Young, P.W. (2016) Prevalence of HIV and Associated Risk Factors Among Long Distance Truck Drivers in Inchope, Mozambique, 2012. AIDS and Behavior, 20, 811-820.

https://doi.org/10.1007/s10461-015-1194-8

[5] Yaya, I., Landoh, D.E., Saka, B., Vignikin, K., Aboubakari, A.-S., N'dri, K.M., et al. (2016) Consistent Condom Use during Casual Sex among Long-Truck Drivers in Togo. PLoS ONE, 11, e0153264. https://doi.org/10.1371/journal.pone.0153264

[6] Atilola, G.O., Akpa, O.M. and Komolafe, I.O.O. (2010) HIV/AIDS and the Long-Distance Truck Drivers in South-West Nigeria: A Cross-Sectional Survey on 
the Knowledge, Attitude, Risk Behaviour and Beliefs of Truckers. Journal of Infection and Public Health, 3, 166-178. https://doi.org/10.1016/j.jiph.2010.08.002

[7] Kelvin, E.A., George, G., Kinyanjui, S., Mwai, E., Romo, M.L., Oruko, F., Odhiambo, J.O., Nyaga, E.N., Mantell, J.E. and Govender, K. (2019) Announcing the Availability of oral HIV Self-Test Kits via Text Message to Increase HIV Testing among Hard-to-Reach Truckers in Kenya: A Randomized Controlled Trial. BMC Public Health, 19, Article No. 7. https://doi.org/10.1186/s12889-018-6345-1

[8] Ishtiaq, R., Asif, A., Jamil, A.R., Irfan, A. and Ishtiaq, D. (2017) Knowledge and Attitude about Sexually Transmitted Infections amongst Truck Drivers in Southern Punjab, Pakistan. Cureus, 9, Article No. e1118. https://doi.org/10.7759/cureus.1118

[9] McCree, D.H., Cosgrove, S., Stratford, D., Valway, S., Keller, N., Vega-Hernandez, J. and Jenison, S.A. (2010) Sexual and Drug Use Risk Behaviors of Long-Haul Truck Drivers and Their Commercial Sex Contacts in New Mexico. Public Health Reports, 125, 52-60. https://doi.org/10.1177\%2F003335491012500108

[10] Michalopoulos, L.M., Ncube, N., Simona, S.J., Kansankala, B., Sinkala, E. and Raidoo, J. (2016) A Qualitative Study of Migrant-Related Stressors, Psychosocial Outcomes and HIV Risk Behaviour among Truck Drivers in Zambia. African Journal of AIDS Research, 15, 219-226. https://doi.org/10.2989/16085906.2016.1179653

[11] Gachohi, J., Aduda, J., Thuo, R., Mung'atu, J., Wamunyokoli, F., Ngigi, T., et al. (2020) Public Health Challenges Posed by Delays in Obtaining COVID-19 Clearance for Long-Distance Truckers across East Africa. Global Epidemiology, 2, Article ID: 100039. https://doi.org/10.1016/j.gloepi.2020.100039

[12] Ramjee, G. and Gouws, E. (2002) Prevalence of HIV among Truck Drivers Visiting Sex Workers in KwaZulu-Natal, South Africa. Sexually Transmitted Diseases, 29, 44-49. https://doi.org/10.1097/00007435-200201000-00008

[13] Knowledge Management \& Communications Capacity (KMMC) (2014) Most at Risk Populations-Long Distance Truck Drivers and HIV/AIDS in Uganda: Synthesis of Information and Evidence to Inform the Response.

https://www.comminit.com/hiv-aids/content/long-distance-truck-drivers-and-hivai ds-uganda-synthesis-information-and-evidence-inform

[14] Rakwar, J., Lavreys, L., Thompson, M.L., Jackson, D., Bwayo, J., Hassanali, S., Mandaliya, K., Ndinya-Achola, J. and Kreiss, J. (1999) Cofactors for the Acquisition of HIV-1 among Heterosexual Men: Prospective Cohort Study of Trucking Company Workers in Kenya. AIDS, 13, 607-614. https://doi.org/10.1097/00002030-199904010-00010

[15] Laukamm-Josten, U., Mwizarubi, B.K., Outwater, A., Mwaijonga, C.L., Valadez, J.J., Nyamwaya, D., Swai, R., Saidel, T. and Nyamuryekung'e, K. (2000) Preventing HIV Infection through Peer Education and Condom Promotion among Truck Drivers and Their Sexual Partners in Tanzania, 1990-1993. AIDS Care, 12, 27-40. https://doi.org/10.1080/09540120047440

[16] Strauss, M., George, G., Mantell, J.E., Romo, M.L., Mwai, E., Nyaga, E.N., Odhiambo, J.O., Govender, K. and Kelvin, E.A. (2018) Stated and Revealed Preferences for HIV Testing: Can Oral Self-Testing Help to Increase Uptake amongst Truck Drivers in Kenya? BMC Public Health, 18, Article No. 1231

https://doi.org/10.1186/s12889-018-6122-1

[17] Ferguson, A.G. and Morris, C.N. (2007) Mapping Transactional Sex on the Northern Corridor Highway in Kenya. Health \& Place, 13, 504-519.

https://doi.org/10.1016/j.healthplace.2006.05.009

[18] World Health Organization (2013) HIV Testing, Treatment and Prevention: Ge- 
neric Tools for Operational Research. World Health Organization, Geneva. https://www.who.int/hiv/pub/operational/generic/en/

[19] Choi, B.C.K. and Pak, A.W.P. (2005) A Catalog of Biases in Questionnaires. Preventing Chronic Disease, 2, A13.

[20] Oppenheim, A.N. (2000) Questionnaire Design, Interviewing and Attitude Measurement. 2nd Edition, Continuum, New York.

[21] Perneger, T.V., Courvoisier, D.S., Hudelson, P.M. and Gayet-Ageron, A. (2015) Sample Size for Pre-Tests of Questionnaires. Quality of Life Research, 24, 147-151. https://doi.org/10.1007/s11136-014-0752-2

[22] R Core Team (2018) The R Project for Statistical Computing. https://www.r-project.org/

[23] Song, M.-K., Lin, F.-C., Ward, S.E. and Fine, J.P. (2013) Composite Variables: When and How. Nursing Research, 62, 45-49. https://doi.org/10.1097/NNR.0b013e3182741948

[24] Romo, M.L., George, G., Mantell, J.E., Mwai, E., Nyaga, E., Strauss, M., Odhiambo, J.O., Govender, K. and Kelvin, E.A. (2019) Depression and Sexual Risk Behavior among Long-Distance Truck Drivers at Roadside Wellness Clinics in Kenya. PeerJ, 7, e7253. https://doi.org/10.7717/peerj.7253

[25] United Nations Programme on HIV/AIDS (UNAIDS) (2020) Global HIV \& AIDS Statistics-2020 Fact Sheet. https://www.unaids.org/en/resources/fact-sheet

[26] Katz, D.A., Dombrowski, J.C., Kerani, R.P., Aubin, M.R., Kern, D.A., Heal, D.D., Bell, T.R. and Golden, M.R. (2016) Integrating HIV Testing as an Outcome of STD. Partner Services for Men Who Have Sex with Men. AIDS Patient Care and STDs, 30, 208-214. https://doi.org/10.1089/apc.2016.0027

[27] Sunmola, A.M. (2005) Sexual Practices, Barriers to Condom Use and Its Consistent Use among Long Distance Truck Drivers in Nigeria. AIDS Care, 17, 208-221. https://doi.org/10.1080/09540120512331325699

[28] Fernández-Balbuena, S., Hoyos, J., Rosales-Statkus, M. E., Nardone, A., Vallejo, F., Ruiz, M., et al. (2016) Low HIV Testing Uptake Following Diagnosis of a Sexually Transmitted Infection in Spain: Implications for the Implementation of Efficient Strategies to Reduce the Undiagnosed HIV Epidemic. AIDS Care, 28, 677-683. https://doi.org/10.1080/09540121.2015.1123808

[29] Mutale, L.S., Chola, M., Chongwe, G., Kasongo, W., Mwakazanga, D.K., Owiny, M., Ajumobi, O.O. and Jacobs, C.N. (2018) Uptake of HIV Testing and Its Associated Factors among Long-Distance Truck Drivers in Zambia, 2015. Journal of Interventional Epidemiology and Public Health, 1, Article No. 8. https://www.afenet-journal.net/content/article/1/8/full/

[30] Bradley, H., Asbel, L., Bernstein, K., Mattson, M., Pathela, P., Mohamed, M., Samuel, M.C., Schwebke, J., Stenger, M., Tabidze, I., Zenilman, J., Dowell, D. and Weinstock, H. (2013) HIV Testing among Patients Infected with Neisseria gonorrhoeae: STD. Surveillance Network, United States, 2009-2010. AIDS and Behavior, 17, 1205-1210. https://doi.org/10.1007/s10461-012-0304-0 


\section{Appendix I: Questionnaire (English Version)}

Thank you for agreeing to participate in this study, which seeks your opinions and thoughts on sexual networks and the utilization of HIV/STIs Preventive services along the Northern Corridor highway. The survey will take approximately 7 - 10 minutes. Please note that participation is voluntary, and your contribution is confidential.

Date of interview DD/MM/YYY

Interview ID number in the form of 001, 002, 003 .

\section{SECTION A}

Socio-demographic and Economic Characteristics

QA.1 How old are you in years. ...?

QA.2 What is your Citizenship?

\section{$\square$ Kenya \\ $\square$ Tanzania \\ $\square$ Uganda \\ $\square$ Rwanda \\ Burundi}

$\square$ DRC

$\square$ South Sudan.

$\square$ Other, specify

$\checkmark$ Declined to answer

QA.3 What was the last level of schooling that you attended?

$\square$ No formal education.

$\square$ Primary education

$\square$ Secondary education

$\square$ Vocational training

$\square$ College

$\square$ University

$\square$ Declined to answer

QA.4 What is your marital status?

$\square$ Single, never married

$\square$ Married

$\square$ Divorced.

$\square$ Widowed

$\square$ Cohabiting

$\square$ Declined to answer

QA.5 What is your religion?

$\square$ Christian.

$\square$ Muslim

$\square$ Hindu

$\square$ Other specify.....

$\square$ Declined to answer

QA.6 For how many years have you worked as a Long-distance truck driver? 
$\square$ Less than a year

1 - 3 years.

$\square 4$ - 5 Years.

$\square 6$ - 10 years.

$\square$ Above ten years

$\square$ Other specify.

$\square$ Declined to answer

QA.7 Would you share with us the number of days or weeks spent on transit before going home?

$\square$ Less than 7 days

$\square$ 1 week

$\square 2$ weeks

$\square 3$ weeks

$\square 4$ weeks and above

$\square$ Other specify.

$\square$ Declined to answer

QA.8 What is your monthly income?

$\square 0$ - 499 USDs (0 - 49,999 KShs)

$\square 500$ - 999 USDs (50,000 Kshs - 99,999 Kshs)

$\square 1000$ - 1999 USDs (100,000 Kshs - 199,999 Kshs)

$\square>2000$ USDs (200,000 Kshs)

$\square$ Declined to answer

\section{Section B}

Factors Related to Frequency of Sexual Interactions.

The next set of questions is about your sexual history and characteristics related to it. By sex, we mean vaginal, oral, or anal sexual intercourse. Please remember that your answers are strictly confidential.

QC.1 During the time you had penetrative sex (anal or vaginal), did you use condoms?

$\square$ Yes

$\square$ No

$\square$ Declined to answer

QC.2 If NO to QC.1 above, would you share to us your reason for not using condoms?

$\square$ Lack of perceived risk of H.I.V./STIs infection from the partner

$\square$ Did not have the condoms

$\square$ Need to have maximized pleasure with unprotected sexual intercourse

$\square$ Declined to answer

$\square$ Other specify.....

QC.3 What would you say were your reasons for sexual engagement while on transit?

$\square$ As a way of relieving stress related to nature of trucking work

$\square$ Urge to meet sexual needs due to prolonged separation from wife or regular sexual partner 
Availability of cheap commercial sex along the highway stopovers

$\square$ Peer influence from fellow truck drivers

$\square$ Declined to answer

Other specify.

QC.4 When you were having sex, had you used any of these substances before or during sex?

$\square$ Alcohol

$\square$ Marijuana

$\square$ Khat (Miraa)

$\square$ Cocaine

$\square$ Other specify

$\square$ Declined to answer

QC.5 Where do you mostly get your condoms from while on transit?

$\square$ Public Health facility (Governmental)

$\square$ Non-Governmental facility (NGO, FBO or a CBO.)

$\square$ Private health facility (Chemists, Clinics or Hospitals)

$\square$ From bars and lodgings

QC.6 Have you ever lacked condoms in a time when you needed them?

$\square$ Yes

$\square$ No

$\square$ Declined to answer

QC.7 What is your main challenge towards access of condoms while on transit?

$\square$ Stockouts from the Public Health Facilities

$\square$ Stockouts from the Non-Governmental facility (NGO, FBO or a CBO.)

$\square$ Unable to afford them from Private facilities (Clinics, or Chemists)

$\square$ Stock out from bars or lodgings

$\square$ Declined to answer

\section{Section C}

Utilization of H.I.V./STIs services and Related Factors

The next set of questions is about the utilization of H.I.V./STDs health care services. Please remember that your answers are strictly confidential.

QD.1 Have you ever been tested on HIV?

$\square$ Yes.

$\square$ No.

$\square$ Declined to answer

QD. 2 If YES to QD.1 above, what type of HIV test was it?

$\square$ Finger prick

$\square$ Oral test

$\square$ Both

$\square$ Declined to answer

QD.3 If your answer to QD.1 is YES, would you tell us when you were lastly tested?

$\square 3$ months ago 
4 - 6 months ago.

$\square$ Above 6 months ago.

$\square$ Declined to answer

QD.4 Would you share with us the outcome of your last HIV test? (If NEGATIVE, skip to QD.8)

$\square$ Negative.

$\square$ Positive

$\square$ Declined to answer

QD.5 If POSITIVE to QD.4 above, were you started on medication from a clinic or any health facility?

$\square$ Yes

$\square$ No

$\square$ Declined to answer

QD.6 If your answer is YES to QD.5 above (started on medication), are you on care and follow up till today?

$\square$ Yes

$\square$ No

$\square$ Declined to answer

QD.7 If your answer to QD6 is NO, would you share with us why?

$\square$ Lack of access to care and treatment

$\square$ Unwilling to take follow up services

$\square$ Difficulties related to nature of trucking Job

$\square$ Declined to answer

$\square$ Other specify

QD.8 Can you recall the type of facility from which you accessed your last HIV testing?

$\square$ Public Health Facility (Governmental)

$\square$ Non-Governmental Facility (NGO, FBO or CBO.)

$\square$ Private health facility (Chemists, Clinics or Hospitals)

$\square$ Do not know.

QD.9 What has been your main challenge while seeking for HIV preventive services?

$\square$ Lack of the required equipment or drugs from health facilities (ART drugs, Test Kits)

$\square$ Lack of a health care provider from the health facility

$\square$ Time delays

$\square$ Negative attitude from the service providers

$\square$ Declined to answer

$\square$ Other specify

QD.10 Have you ever had a sexually transmitted infection (Burning sensation during urination or penile discharge associated with unprotected sexual intercourse).

$\square$ Yes

$\square$ No 
Declined to answer

QD.11 If YES to QD.10 above, did you seek for treatment?

$\square$ Yes

$\square$ No

$\square$ Declined to answer

QD.12 If YES to QD.11 above, from which of these facilities did you seek treatment from?

$\square$ Public Health facility (Governmental)

$\square$ Non-Governmental facility (NGO, FBO or a CBO.)

$\square$ Private health facility (Chemists, Clinics or Hospitals)

$\square$ Declined to answer

QD.13 After how long did you seek for the STI treatment

$\square 1$ - 7 days

$\square 1$ - 2 Week

$\square$ More than two weeks

$\square$ Declined to answer

QD.14 What is your main challenge while accessing STI treatment while on transit?

$\square$ Lack of access to the drugs and health care facilities

$\square$ Lack of funds for the health care service

$\square$ Lack of Health insurance cover

$\square$ Negative attitude from the health service providers

$\square$ Declined to answer

$\square$ Other specify.

This brings us to the conclusion of our interview.

Thank you for participating. 